\title{
Squalestatin alters the intracellular trafficking of a neurotoxic prion peptide

\author{
Rona Wilson ${ }^{1}$, Clive Bate ${ }^{2}$, Ronald Boshuizen ${ }^{3}$, Alun Williams ${ }^{2}$ and \\ James Brewer*4
}

Address: ${ }^{1}$ Division of Immunology, Infection and Inflammation, Western Infirmary, University of Glasgow, G11 6NT, Glasgow, ${ }^{2}$ Department of Pathology and Infectious Diseases, Royal Veterinary College, Hawkshead Lane, North Mymms, AL9 7TA, Herts, ${ }^{3}$ Pepscan systems B.V, Edelhertweg 15, 8219 PH, Lelystad, The Netherlands and ${ }^{4}$ Centre for Biophotonics, Strathclyde Institute for Biomedical Sciences, University of Strathclyde, G4 ONR, Glasgow

Email: Rona Wilson -rkw1m@clinmed.gla.ac.uk; Clive Bate - cbate@rvc.ac.uk; Ronald Boshuizen - Ronald.Boshuizen@wur.nl; Alun Williams - alunwilliams@RVC.AC.UK; James Brewer* - james.brewer@strath.ac.uk

* Corresponding author

Published: 22 November 2007

BMC Neuroscience 2007, 8:99 doi:10.1/86/147|-2202-8-99
Received: 7 December 2006

Accepted: 22 November 2007

This article is available from: http://www.biomedcentral.com/147I-2202/8/99

(c) 2007 Wilson et al; licensee BioMed Central Ltd.

This is an Open Access article distributed under the terms of the Creative Commons Attribution License (http://creativecommons.org/licenses/by/2.0), which permits unrestricted use, distribution, and reproduction in any medium, provided the original work is properly cited.

\begin{abstract}
Background: Neurotoxic peptides derived from the protease-resistant core of the prion protein are used to model the pathogenesis of prion diseases. The current study characterised the ingestion, internalization and intracellular trafficking of a neurotoxic peptide containing amino acids 105-I32 of the murine prion protein (MoPrPI05-I32) in neuroblastoma cells and primary cortical neurons.
\end{abstract}

Results: Fluorescence microscopy and cell fractionation techniques showed that MoPrPI05-I32 co-localised with lipid raft markers (cholera toxin and caveolin-I) and trafficked intracellularly within lipid rafts. This trafficking followed a non-classical endosomal pathway delivering peptide to the Golgi and ER, avoiding classical endosomal trafficking via early endosomes to lysosomes. Fluorescence resonance energy transfer analysis demonstrated close interactions of MoPrPI05132 with cytoplasmic phospholipase $A_{2}\left({ }^{2} P L A_{2}\right)$ and cyclo-oxygenase-I (COX-I), enzymes implicated in the neurotoxicity of prions. Treatment with squalestatin reduced neuronal cholesterol levels and caused the redistribution of MoPrPI 05 - I 32 out of lipid rafts. In squalestatintreated cells, MoPrPI05-132 was rerouted away from the Golgi/ER into degradative lysosomes. Squalestatin treatment also reduced the association between MoPrPI05-I32 and cPLA $/$ COX-I.

Conclusion: As the observed shift in peptide trafficking was accompanied by increased cell survival these studies suggest that the neurotoxicity of this PrP peptide is dependent on trafficking to specific organelles where it activates specific signal transduction pathways.

\section{Background}

The Transmissible Spongiform Encephalopathies (TSE)s, otherwise known as prion diseases, are a family of neurodegenerative diseases that include Creutzfeldt-Jakob disease (CJD) in man, Bovine Spongiform Encephalopathy
(BSE) in cattle, and scrapie in sheep and goats. A notable feature of these diseases is the accumulation of $(\mathrm{PrPsc})[1]$, a misfolded isoform of the host-encoded prion protein $\operatorname{PrPc}[2,3]$. Neuronal dysfunction and ultimately neuronal death are thought to arise following deposition of fibrils 
of PrPSc which accumulate in the brain of infected animals [4-6]. However, it remains unclear if $\mathrm{PrPSc}^{\mathrm{Sc}}$ causes neuronal damage itself, or acts via other molecular forms of PrP that have been suggested as causative agents in prion disease [7-9].

The process of neuronal loss can be investigated in vitro using highly defined synthetic peptides derived from the protease-resistant core of $\mathrm{PrPSc}^{\mathrm{Sc}}$. The majority of neurotoxicity studies have employed a peptide consisting of amino acids 106-126 of the human prion protein (HuPrP106126) which possesses many of the properties of the $\operatorname{PrPSc}$ isoform, notably a high $\beta$-pleated sheet content, fibril formation and toxicity for neurons in vitro [7]. A corresponding peptide has been identified from the murine prion sequence (MoPrP105-132), which has also been shown to be neurotoxic [8]. These peptides also encompass the major part of the putative transmembrane form of $\operatorname{PrP}$ ( $\left.{ }^{\mathrm{Ctm} P r P}\right)$ that is thought to be important in prion disease pathogenesis as transgenic mice overexpressing such $\operatorname{PrP}$ molecules develop neurological disease, and the accumulation of PrPres is followed closely by an increase in CtmPrP $[10,11]$. In the current study we employed labelled MoPrP105-132 to identify organelles involved in the trafficking pathways of neurotoxic peptides. We demonstrate that in neuroblastoma cells, MoPrP105-132 co-localises with cholera toxin subunit $\mathrm{B}(\mathrm{CTxB})$, which binds to the ganglioside GM1 [12,13] and caveolin-1 [14,15], markers of specialised microdomains called lipid rafts.

Lipid rafts are highly enriched in cholesterol, sphingolipids and a population of specific membrane proteins [16]. In some cells, lipid rafts contain cholesterol-binding proteins called caveolins that define a subset of lipid raft called caveosomes [17]. Lipid rafts also act as platforms for cell signalling processes $[18,19]$, suggesting that MoPrP105-132 might interact with signalling enzymes. As a close correlation exists between the production of prostaglandins (PG)s and neuronal death in prion disease $[20,21]$, the association between MoPrP105-132 and the enzymes PLA $\mathrm{A}_{2}$ and COX responsible for the release of arachidonic acid (AA) and the metabolism of AA into PGs respectively, were studied.

There is increasing evidence that cholesterol levels within the brain may affect the progression of some neurodegenerative diseases. Cholesterol depletion in vitro has been shown to affect the integrity of lipid rafts $[22,23]$ and reducing cellular cholesterol levels reduces the sensitivity of neurons to prions [23]. In the following studies we have demonstrated that pre-treatment of neurons with squalestatin, a drug that inhibits cholesterol production [24], alters the surface localisation and the intracellular trafficking of the MoPrP105-132 peptide. In addition, pretreatment with squalestatin significantly reduced the asso- ciation between MoPrP105-132 and $\mathrm{CPLA}_{2}$ or COX-1. Such observations raise the possibility that the neurotoxicity of PrP peptides is dependent on the specific intracellular trafficking pathways of such peptides and the association with signal transduction pathways.

\section{Results}

MoPrPI05-I32 is located within lipid rafts

Initial studies demonstrated that to achieve internalisation and detection of labelled MoPrP105-132 in greater than $50 \%$ of the NB4 cells required at least $30-90$ minutes incubation at $37^{\circ} \mathrm{C}$ (data not shown). Following this incubation period, $63 \% \pm 8$ of rhodamine-labelled MoPrP105-132 co-localised with Alexa Fluor 488 labelled $\mathrm{CTxB}$, which binds to ganglioside-GM1 and identifies lipid rafts [13-15] (Figure 1A). In contrast, no co-localisation between scrambled MoPrP105-132 and CTxB was detected (Figure 1B), indicating that the localisation of MoPrP105-132 in lipid rafts was dependent on the primary sequence of the peptide. To confirm these findings on non-transformed cells, further experiments were conducted using primary cortical neurons; comparable results were obtained (see additional files 1A \&1B). A FRET signal generated between acceptor-conjugated MoPrP105-132 and donor conjugated $\mathrm{CTxB}$ indicated that the two molecules were in close association, approximately 10-100 (Figures 1C, 1D). In contrast, no FRET signal could be detected between scrambled MoPrP105-132 and CTxB (data not shown). To determine whether caveolae played a role in the trafficking of MoPrP105-132, neuroblastoma cells were incubated with rhodamine-labelled MoPrP105132 for 30 minutes, fixed and probed with FITC labelled anti-caveolin-1. We found $73 \% \pm 3$ of MoPrP105-132 colocalised with caveolin-1 (Fig 1E). Furthermore, a FRET signal between MoPrP105-132 and caveolin-1 was also detected confirming the close association of these molecules (Figures 1F \&1G). The fluorescence microscopy studies were complemented by lipid rafts isolation studies on MoPrP105-132 treated neuroblastoma cells. Following incubation for 30 minutes, MoPrP105-132 was found in a TfR negative, caveolin- 1 and CTxB positive fraction (Figure 1H). These results confirm that MoPrP105-132 can be found in lipid rafts and that caveolin-1 was also present in the lipid rafts that were isolated.

\section{MoPrPI05-I32 traffics via a non-classical endocytic pathway}

The intracellular trafficking pathway of MoPrP105-132 was further investigated by incubating biotin-conjugated MoPrP105-132 for 1 hour at $37^{\circ} \mathrm{C}$ before fixation. Fluorescence microscopy showed that only $6 \% \pm 3$ of MoPrP105-132 localised in TfR positive early endosomes (Figure 2A) and only 9\% \pm 2 of MoPrP105-132 co-localised within LAMP-1 positive lysosomes (Figure 2B). In contrast, $77 \% \pm 6$ of scrambled MoPrP105-132 was asso- 

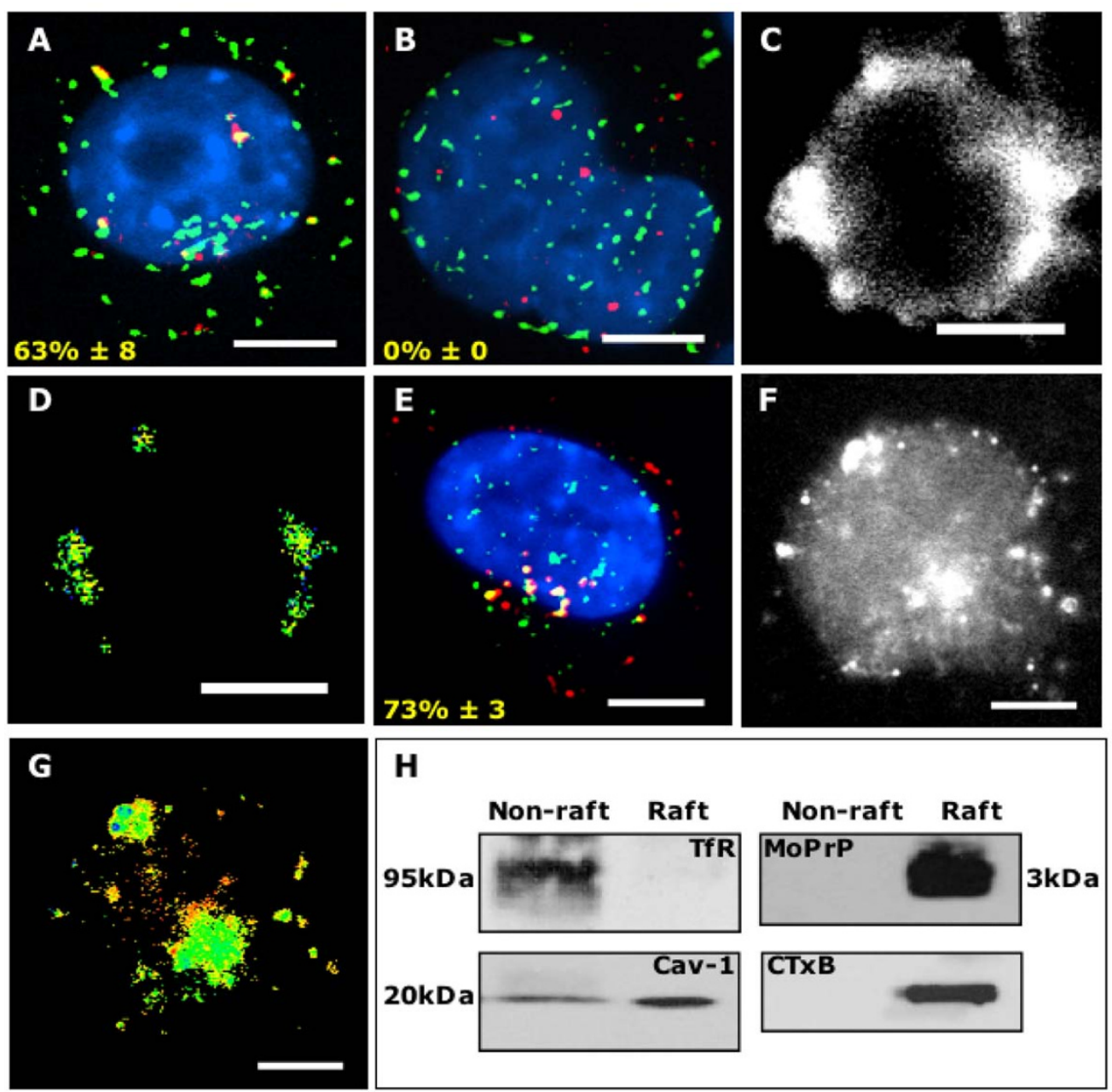

\section{Figure I}

MoPrP I $05-132$ is found in lipid rafts. Neuroblastoma cells incubated for 30 minutes with $30 \mu$ M rhodamine-labeled MoPrPI05-I 32 and Alexa Fluor 488 labelled CTxB for 30 minutes, the nuclei were revealed using Vectashield with DAPI (blue). (A) Images of MoPrPI05-I 32 (red) and CTxB (green) staining were merged using OpenLab software to show co-localization (yellow). (B) Images of scrambled MoPrPI05-I 32 (red) and CTxB (green) staining showed that there was no co-localization (yellow). (C) FRET analysis showing the raw data between rhodamine-labeled MoPrPI05-I32 and Alexa Fluor 488 labelled $\mathrm{CT} \times \mathrm{B}$ and (D), the proximity of the donor/acceptor reaction revealed by false-colour intensity. Images of neuroblastoma cells incubated for 30 minutes with $30 \mu \mathrm{M}$ rhodamine-labeled MoPrPI05-I 32 (red) and stained with FITC-labelled anti-caveolin-I (green), showing co-localization (yellow). (E) FRET analysis showing the raw data between rhodamine-labeled MoPrPI05-I32 and FITC-labelled CTxB and (F), the proximity of the donor/acceptor reaction revealed by false-colour intensity. Scale bars, 5 $\mu \mathrm{m}$. $(\mathrm{H})$, Western-blot analysis of triton $X-100$ insoluble fractions (lipid rafts) and soluble fractions (non-raft) isolated from neuroblastoma cells incubated with $30 \mu$ M MoPrPI05-I32-FITC for 30 minutes, and probed for MoPrPI05-I32, caveolin- I, TfR and GMI (CTxB).

ciated with LAMP-1 positive lysosomes (Figure 2C), confirming the sequence dependence of MoPrP105-132 localisation. Comparable results were obtained in primary cortical neurons (see additional files 2A, 2B). After 90 minutes at $37^{\circ} \mathrm{C}$, approximately $41 \% \pm 5$ of MoPrP105-132 co-localised with GM130, a marker for cis-Golgi (Fig 2D) and 38\% \pm 4 with Grp78, which identifies the ER (Fig 2E). These findings are consistent with previous reports that that molecules internalised in lipid rafts traffic to the Golgi/ER [25]. The microscopy studies were complemented by an endosomal fractionation technique, as previously described [26]. In neuroblastoma cells incubated with MoPrP105-132 for 1 hour at $37^{\circ} \mathrm{C}$, MoPrP105-132 was detected in the whole microsomal extract and the cell fraction known to be enriched for Golgi and ER compartments [27], but was not found in 
either TfR positive or LAMP-1 positive fractions (Figure 2F).

\section{Squalestatin treatment alters MoPrPI 05-I32 trafficking}

Previous studies have shown that depletion of cholesterol in neurones protects against the neurotoxicity induced by prion peptides [23], including MoPrP105-132 (see additional data 3 ). To determine whether squalestatin was simply altering the quantity of MoPrP105-132 ingested, squalestatin treated or untreated neuroblastoma cells were incubated with $30 \mu \mathrm{M}$ MoPrP105-132 conjugated to FITC. The levels of cell associated fluorescence in each condition was determined after 30 minutes incubation by FACS analysis of cells and expressed as arbitrary units of mean fluorescence intensity. There was no significant difference between the mean fluorescence intensity for untreated and squalestatin treated cells $(23.2 \pm 2$ compared to $25.3 \pm 4, \mathrm{n}=6, \mathrm{P}>0.05$ ). As a number of studies
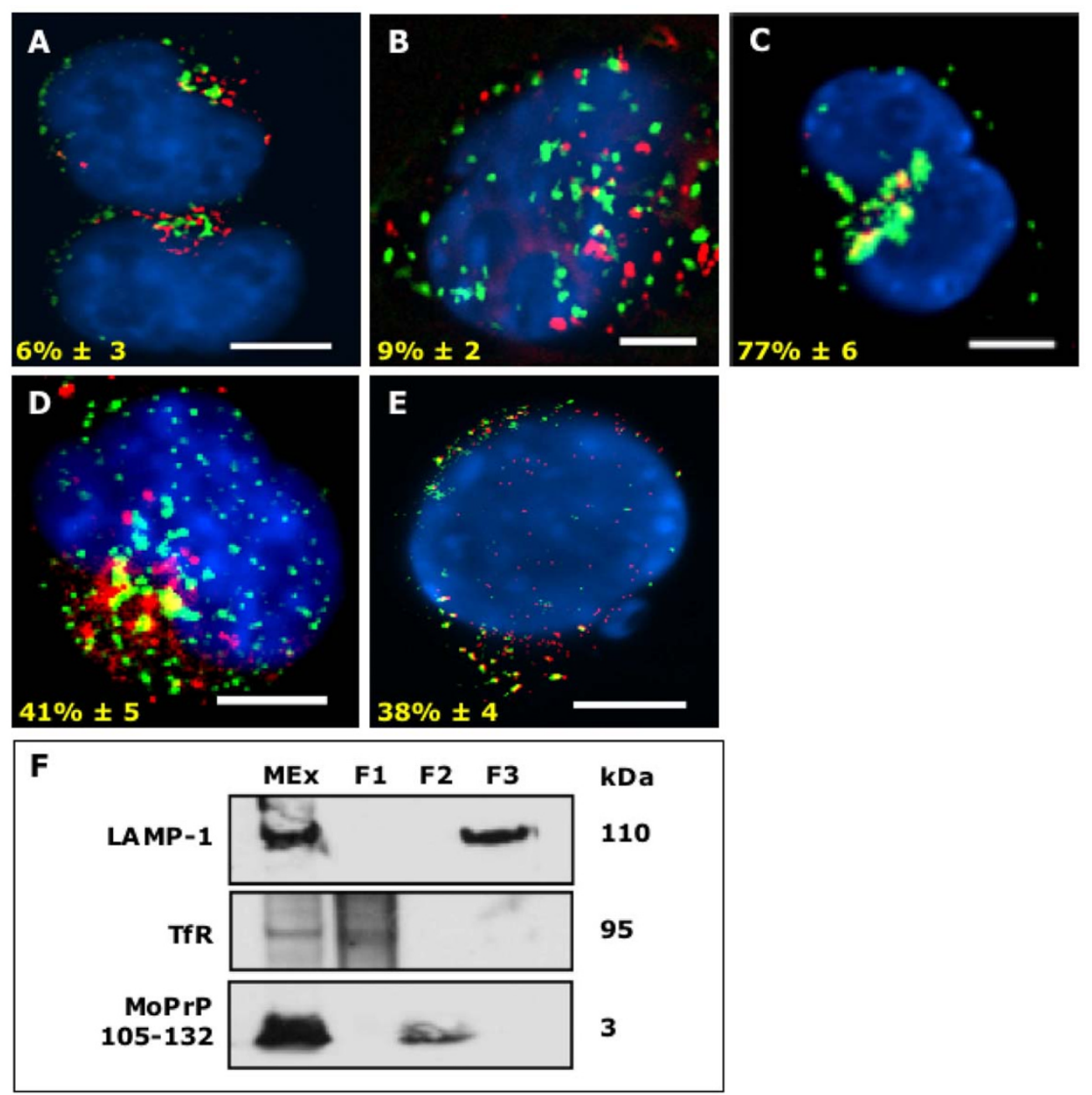

\section{Figure 2}

MoPrP I 05 - I 32 avoids early endosomes and lysosomes. Neuroblastoma incubated with biotinylated MoPrPI05-I32 at $37^{\circ} \mathrm{C}$, then fixed and stained with Texas Red-streptavidin (red) and TfR-FITC (green) or LAMP-I-FITC (green). Nuclei were revealed using Vectashield with DAPI (blue). (A) Co-localisation (yellow) was not observed between MoPrPI05-I32 and TfR or (B) between MoPrPI05-I 32 and LAMP-I. (C) Co-localisation of biotinylated scrambled MoPrPI05-I32 (red) with LAMP-I (green) was evident. Neuroblastoma cells were incubated with biotinylated MoPrPI05-I32 (red) for 90 minutes, then fixed and stained with GMI30 (green) or Grp78 (green). (D) Co-localisation was observed between MoPrPI05-I32 and GMI30 and (E) between MoPrPI05-I32 and Grp78. Scale bars, $5 \mu \mathrm{m}$. (F) Separation of endosomal compartments. Neuroblastoma cells were pulsed with iron dextran beads, before incubation with MoPrPI05-I32-FITC for I hour. Lysosomes (F3) were extracted from whole microsome extracts (MEx) using a magnetic column and early endosomes (FI) and intermediate fraction (F2) isolated using a density gradient. Western blot analysis revealed MoPrPI05-I32 was present in TfR negative and LAMP-I negative fractions (F2). 
have demonstrated that lipid rafts involved in internalisation and trafficking are cholesterol sensitive, the effect of squalestatin on the intracellular trafficking of MoPrP105132 was investigated. Following pre-treatment with squalestatin, neuroblastoma cells were incubated with $\mathrm{CTxB}$ and MoPrP105-132 for 30 minutes at $37^{\circ} \mathrm{C}$. Fluorescence microscopy revealed that in squalestatin-treated cells only $5 \% \pm 1$ of the MoPrP105-132 co-localised with CTxB (Figure $3 \mathrm{~A}$ ), whereas $75 \% \pm 7$ of MoPrP105-132 co-localised with $\mathrm{CTxB}$ in untreated neuroblastoma cells (Figure 3B). When lipid rafts were isolated from neuroblastoma cells that had been pre-treated with squalestatin, most of the MoPrP105-132 was detected in the non-raft fraction, while CTxB and caveolin-1 were present in both raft and non-raft fractions (Figure 3C). Such findings suggest that the localisation of MoPrP105-132 to lipid rafts is sensitive to cholesterol depletion.

Further analysis of the trafficking of MoPrP105-132 in squalestatin-treated neuroblastoma cells showed that only $7 \% \pm 2$ of MoPrP105-132 co-localised with the Golgi (Figure 4A) and 3\% \pm 2 of MoPrP105-132 co-localised
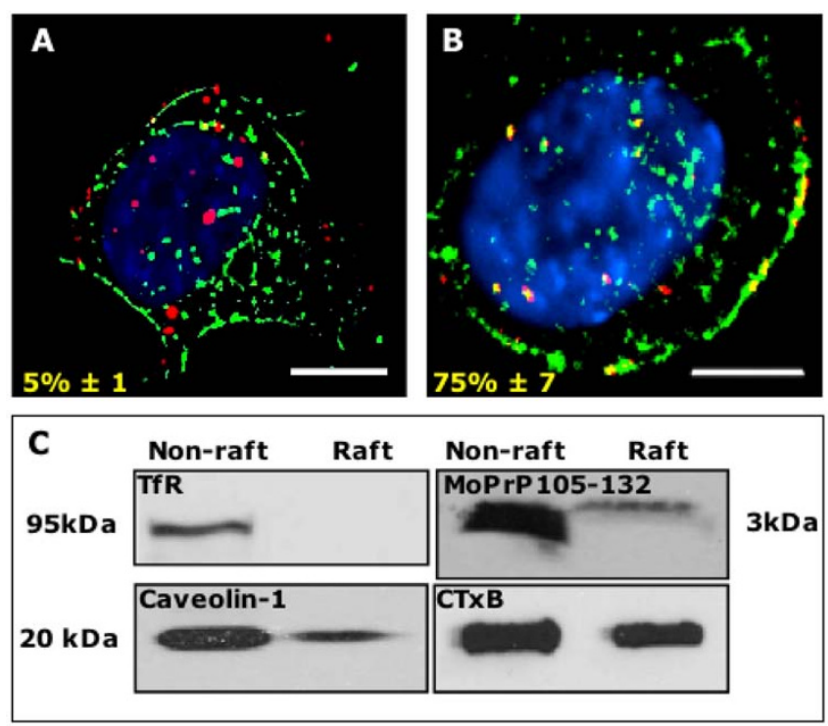

Figure 3

Squalestatin reduces the distribution of MoPrP I05I 32 and CTxB in neuroblastoma cells. Neuroblastoma cells were incubated with I $\mu$ M squalestatin for 24 hours and subsequently incubated with MoPrPI 05- I32-rhodamine (red) and CTxB-Alexa Fluor 488 (green), nuclei were revealed using Vectashield with DAPI (blue). (A) Lack of co-localisation was apparent between MoPrPI05-I32 and CTxB in squalestatin treated cells compared with (B) untreated cells. Scale bar, $5 \mu \mathrm{m}$. (C) Isolation of lipid raft/non-raft membranes from neuroblastoma cells treated with I $\mu \mathrm{M}$ squalestatin for 24 hours. In squalestatin-treated cells the majority of MoPrPI05-I 32 was present in the non-raft fraction. with the ER (Figure 4B), suggesting that in these cells MoPrP105-132 does not undergo retrograde trafficking. We found that $68 \% \pm 8$ of MoPrP105-132 co-localised with early endosomes (Figure 4C) and $40 \% \pm 6$ of MoPrP105-132 co-localised with lysosomes (Figure 4D). These observations suggest that in squalestatin-treated cells the MoPrP105-132 peptide is diverted away from retrograde transport to the Golgi/ER and directed into the classical endosome/lysosomal degradative pathway. A
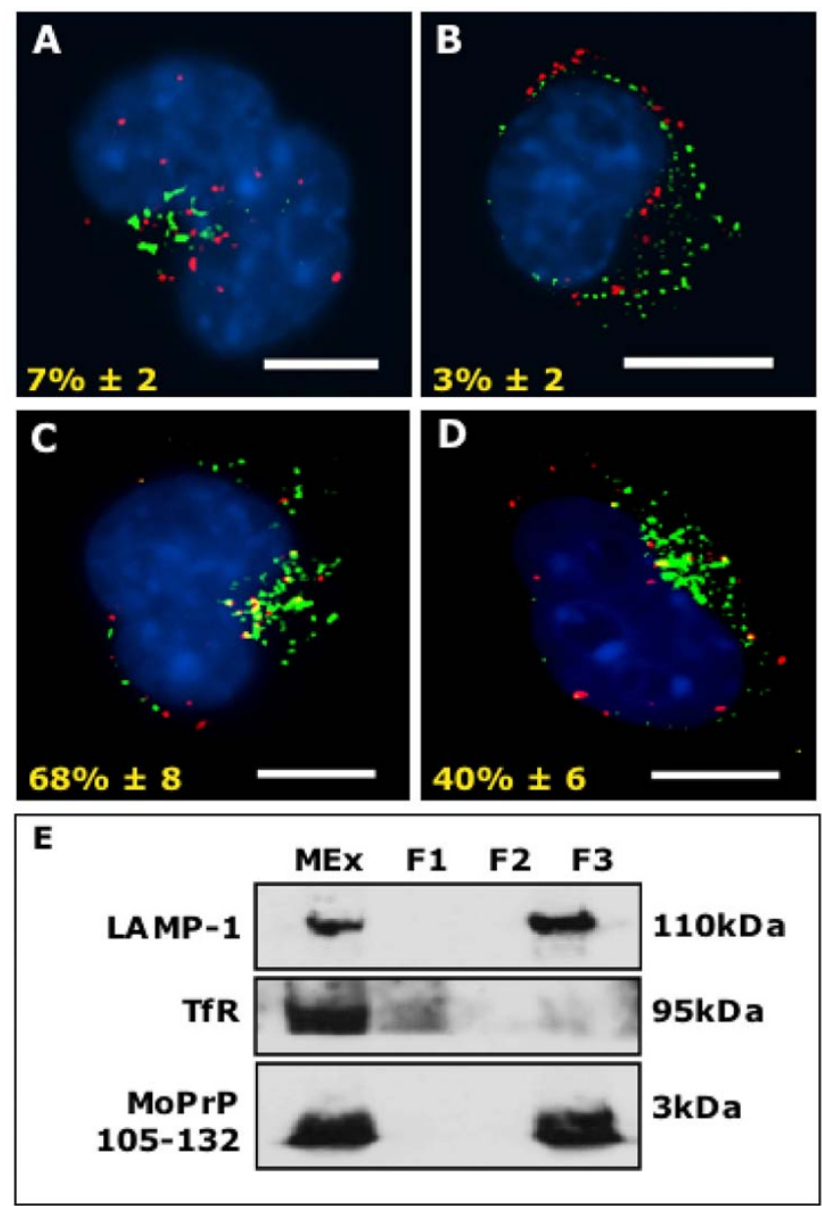

Figure 4

Squalestatin reroutes MoPrP I 05 - I 32 into lysosomes. Neuroblastoma cells were incubated with I $\mu$ M squalestatin for 24 hours before incubation with $30 \mu \mathrm{M}$ MoPrPI05-I32biotin for 90 minutes, then fixed and stained with Texas Redstreptavidin (red) and with anti-GMI30, anti-Grp78, antiTfR-FITC or anti-LAMP-I-FITC (all green) (A) Co-localisation between MoPrPI05-I32 and GMI30, or (B) between MoPrPI05-I 32 and Grp78. (C) In squalestatin treated cells co-localisation was observed between MoPrPI05-I 32 and TfR and (D) between MoPrPI05-I32 and LAMP-I. Scale bars, $5 \mu \mathrm{m}$. (E) In squalestatin-treated cells, following fractionation of whole microsomal extracts (MEx) using iron dextran and density gradient centrifugation, MoPrPI05-I 32 was detected in the lysosome fraction (F3). 
summary of the differences in the trafficking pathways of MoPrP105-132 in untreated and squalestatin-treated neuroblastoma cells is presented as Table 1 . The re-routing of MoPrP105-132 to the classical endocytic pathway in squalestatin-treated cells was confirmed by analysis of endosomal fractions. In endosomal fractions isolated from squalestatin-treated neuroblastoma cells pulsed with MoPrP105-132 for 1 hour, MoPrP105-132 was detected in the LAMP-1 positive, TfR negative, lysosomal fraction (Figure 4E).

\section{MoPrPI05-I32 associates with CPLA ${ }_{2}$ and COX-I}

Since a close association exists between PG's and prioninduced neurotoxicity [28-31], the relationship between MoPrP105-13 and enzymes involved in the production of PGs was examined. Neuroblastoma cells were incubated with MoPrP105-132 for either 5 minutes or 20 minutes at $37^{\circ} \mathrm{C}$, fixed, and stained with antibodies to either $\mathrm{CPLA}_{2}$ or COX-1. After 5 minutes $38 \% \pm 7$ of MoPrP105-132 colocalised with $\mathrm{CPLA}_{2}$ (Figure $5 \mathrm{~A}$ ) and $70 \% \pm 5$ of MoPrP105-132 co-localised with COX-1 (Figure 5C). After 20 minutes only $2 \% \pm 1$ of MoPrP105-132 co-localised with $\mathrm{CPLA}_{2}$ (Figure 5B) and no co-localisation was observed between MoPrP105-132 and COX-1 (Figure 5D), indicating that the association between MoPrP105132 and CPLA $_{2}$ or COX-1 was short lived.

\section{Squalestatin treatment reduces the association between MoPrPI05-132 and CPLA $/$ COX-I}

Since treatment with squalestatin protected neurons against prions [23] the effects of squalestatin on the colocalisation between MoPrP105-132 and $\mathrm{CPLA}_{2}$ was examined 5 minutes after the addition of peptide. Pretreatment with $1 \mu \mathrm{M}$ squalestatin significantly reduced the association between MoPrP105-132 and $\mathrm{CPLA}_{2}(13 \% \pm 4$ compared with $38 \% \pm 7$ in untreated cells) (Figure 6A). Similarly, pre-treatment with squalestatin reduced the association between MoPrP105-132 and COX-1 (5\% \pm 5

Table I: Squalestatin alters the trafficking of MoPrP I 05-1 32 in neuroblastoma cells. The percentage of MoPrPI 05-I32 that colocalised with cellular markers as shown in untreated neuroblastoma cells and cells treated for 24 hours with I $\mu$ M squalestatin. Values shown are mean percent of peptide that colocalises with markers as shown, \pm SD, which was calculated after counting a minimum of 3 cells.

\begin{tabular}{ccc}
\hline & \multicolumn{2}{c}{$\%$ Co-localisation with MoPrP I05-I32 } \\
\cline { 2 - 3 } & Untreated & Squalestatin-treated \\
\hline CTxB & $63 \% \pm 8$ & $5 \% \pm 1$ \\
Caveolin-I & $73 \% \pm 3$ & $9 \% \pm 3$ \\
GMI30 & $41 \% \pm 5$ & $7 \% \pm 2$ \\
Grp 78 & $38 \% \pm 4$ & $3 \% \pm 2$ \\
TfR & $6 \% \pm 3$ & $68 \% \pm 8$ \\
LAMP-I & $9 \% \pm 2$ & $40 \% \pm 6$ \\
\hline
\end{tabular}
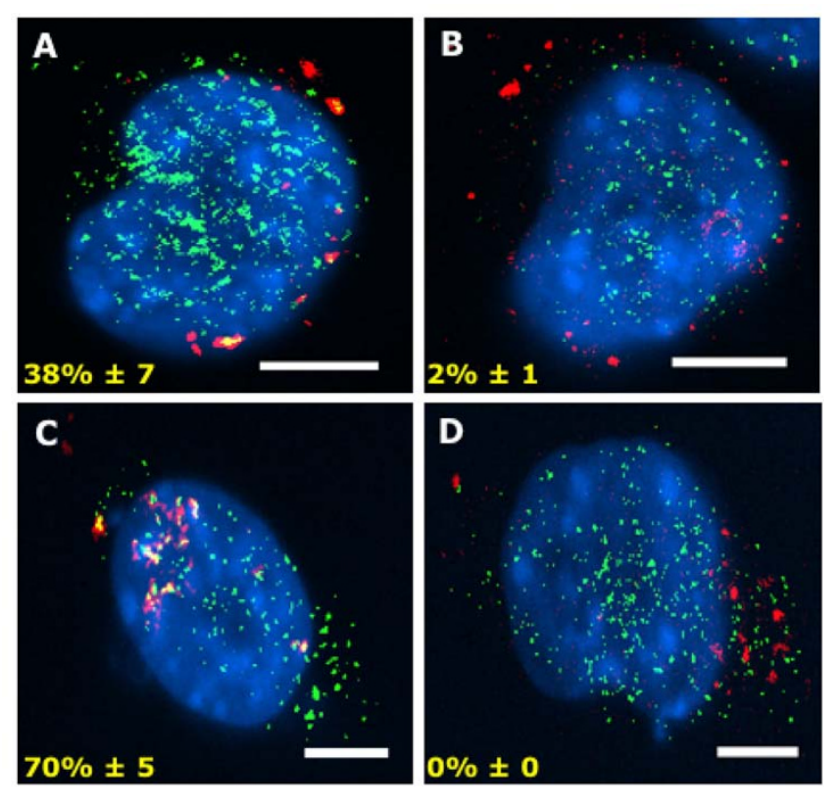

\section{Figure 5}

MoPrP I 05 - I 32 associates with CPLA 2 and COX-I. Neuroblastoma cells were incubated with $30 \mu \mathrm{M}$ MoPrPI05I32-biotin for 5 minutes or 20 minutes at $37^{\circ} \mathrm{C}$ then fixed and stained with Texas Red-streptavidin (red), anti-cPLA ${ }_{2}-$ FITC (green) or anti-COX-I-FITC (green). Nuclei were revealed using Vectashield with DAPI (blue). (A) Co-localisation (yellow) between MoPrPI05-I 32 (red) and cPLA 2 (green) after 5 minutes, but not after 20 minutes (B). (C) Colocalisation (yellow) between MoPrPI05-I 32 (red) and antiCOX-I-FITC (green) after 5 minutes, but not after 20 minutes (D). Scale bars, $5 \mu \mathrm{m}$.

compared to $70 \% \pm 5$ in untreated cells) (Figure 6B). Neurons treated with PAF antagonists are also resistant to the otherwise toxic effects of prions [23] and pre-treatment with $2 \mu \mathrm{M}$ of a PAF antagonist (Hexa-PAF) reduced the association between MoPrP105-132 and $\mathrm{CPLA}_{2}(22 \% \pm 6$ $\mathrm{v} 38 \% \pm 7$ in untreated cells) (Figure $6 \mathrm{C}$ ). Treatment with Hexa-PAF also reduced the association between MoPrP105-132 and COX-1 (13\% \pm 3 compared to $70 \% \pm$ 5 in untreated cells) (Figure 6D). A summary of the differences in co-localisation between MoPrP105-132 and the signalling enzymes in untreated and squalestatin-treated neuroblastoma cells is presented as Table 2 .

\section{Discussion}

Although neuronal dysfunction and ultimately neuronal loss are key features of prion diseases, the molecular mechanisms that that result in neuronal damage remain poorly understood. Synthetic peptides have been extensively used to model the process of neuronal degeneration in vitro and in the present study we analysed the trafficking of MoPrP105-132 in neuroblastoma cells and primary 

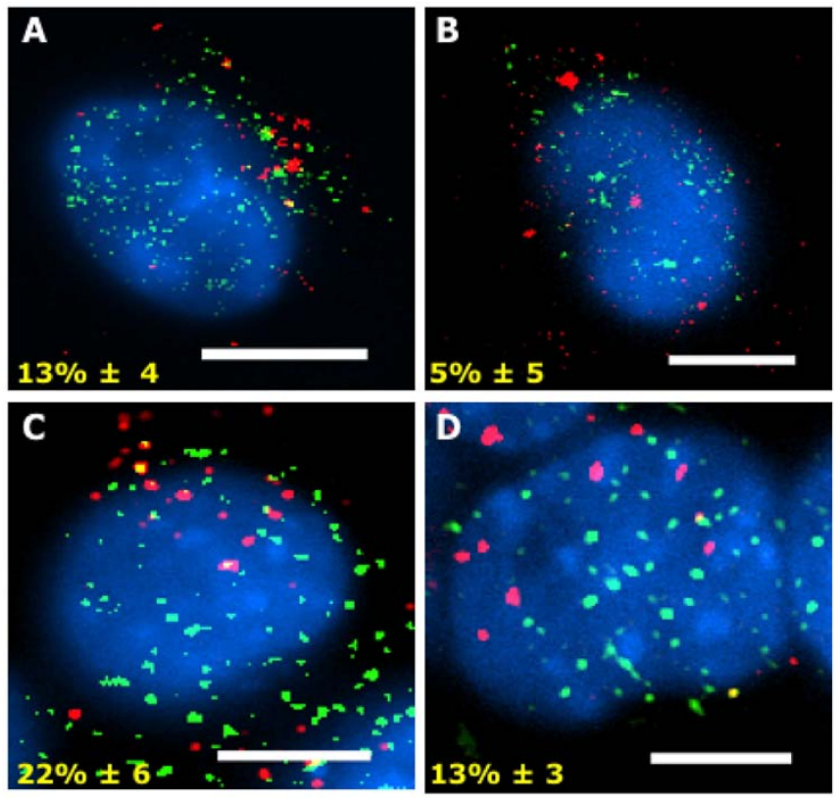

Figure 6

Squalestatin reduces the association between MoPrPI $05-132$ and CPLA 2 and COX-I. Neuroblastoma cells were pre-treated with either I $\mu \mathrm{M}$ squalestatin or $2 \mu \mathrm{M}$ Hexa-PAF prior to incubation with $30 \mu \mathrm{M}$ MoPrPI05-I32biotin for 5 minutes at $37^{\circ} \mathrm{C}$, fixed and stained with Texas Red-streptavidin (red) anti-cPLA ${ }_{2}$-FITC or anti-COX-I-FITC (green). Nuclei were revealed using Vectashield with DAPI (blue). Images show the extent of co-localisation (yellow) between MoPrPI05-I 32 (red) and cPLA 2 (green) (A) or between MoPrPI05-I 32 (red) and COX-I (green) (B) in squalestatin-treated cells. Similarly, images show the extent of co-localisation (yellow) between MoPrPI05-I 32 (red) and cPLA $_{2}$ (green) (C) or between MoPrPI05-I32 (red) and COX-I (green) (D) in Hexa-PAF-treated cells. Scale bars, 5 $\mu \mathrm{m}$.

cortical neurones. Most of the MoPrP105-132 molecules co-localised with ganglioside GM1, a marker of lipid rafts identified by CTxB, and with caveolin-1, a marker of a lipid raft subset called caveolae. FRET analysis, a tech-

Table 2: Squalestatin reduces co-localisation between

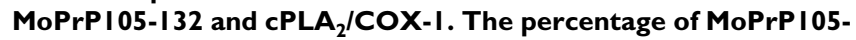
I 32 that co-localised with the signalling enzymes CPLA $A_{2}$ or COX$I$ in untreated neuroblastoma cells and cells treated for 24 hours with either I $\mu$ M squalestatin or 2 Hexa-PAF, 5 minutes after the addition of peptide. Values shown are mean $\pm S D$, calculated after counting a minimum of 3 cells.

\begin{tabular}{cccc}
\hline $\begin{array}{c}\text { Co-localisation with } \\
\text { MoPrPI05-132 }\end{array}$ & \multicolumn{3}{c}{ Drug Treatments } \\
\cline { 2 - 4 } & Untreated & Squalestatin & Hexa-PAF \\
\hline cPLA 2 & $38 \% \pm 7$ & $13 \% \pm 4$ & $22 \% \pm 6$ \\
COX-I & $70 \% \pm 5$ & $5 \% \pm 5$ & $13 \% \pm 3$ \\
\hline
\end{tabular}

nique with spatial resolution beyond the limits of conventional fluorescence imaging, demonstrated that MoPrP105-132 was intimately associated with both GM1 and caveolin-1 (minimal spacing of 10-100 A required to observe FRET signals). Separation of lipid rafts from cell membranes by detergent extraction confirmed the microscopy data (MoPrP105-132 was detected only in the GM1 and caveolin-1 positive fraction). It not clear why MoPrP105-132 localises to lipid rafts, one possibility is that lipid rafts contain a high percentage of saturated fatty acids, which provides a hydrophobic environment that stabilises the peptide within the membrane. Another possibility is that many of the putative receptors for prions [32] are found within lipid rafts, thus, peptide-receptor interactions may be responsible for targeting MoPrP105132 to these domains.

The trafficking of molecules within cells is partly dependent on the mechanism of internalisation, thus, molecules that are ingested via clathrin-dependent endocytosis traffic via endosomes into degradative lysosomes [33]. In contrast, agents targeted to lipid rafts or caveolae are internalised by clathrin-independent endocytosis and traffic into different cellular compartments. MoPrP105-132 trafficked into both the Golgi and ER (co-localised with the markers GM130 and Grp78); consistent with reports that the cargo of caveolae is directed into the Golgi $[14,15,34]$. These results are consistent with MoPrP105-132 trafficking via the non-classical endocytic pathway, recently defined through the trafficking of GM1 positive lipid rafts [12]. Only a small percentage of MoPrP105-132 was associated with either TfR or LAMP-1, indicating that it was rarely found in early endosomes or lysosomes. Microscopy data was supported by organelle fractionation studies in which endosomes involved in the classical endocytic pathways were fractionated. MoPrP105-132 was not found in fractions containing either TfR or LAMP1 , but was found in an intermediate density fraction known to contain Golgi/ER [27]. Taken together these results indicate that MoPrP105-132 does not traffic down the classical endocytic route and avoids the lysosomes. We speculate that the avoidance of proteolytic lysosomes may facilitate the build up of neurotoxic peptides during disease progression. The localisation of MoPrP105-132 to lipid rafts depends on the sequence of amino acids as a control peptide made up of the same amino acids synthesized in a scrambled sequence did not localise within lipid rafts. Subsequently, the scrambled MoPrP105-132 control peptide trafficked to endosomes and lysosomes, emphasising the sequence dependent nature of the intracellular trafficking of the peptide. Although most of the studies presented are on neuroblastoma cells we found that MoPrP105-132 trafficked in a similar manner in nontransformed primary cortical neurones. The sequence specificity of this effect would argue against MoPrP non-spe- 
cifically associating with lipid rafts through for example, hydrophobicity, as the composition of the scrambled peptide was the same as MoPrP105-132.

Previous studies demonstrated that neurons treated with the cholesterol synthesis inhibitor squalestatin, a drug that inhibits squalene synthase and reduces cholesterol production without affecting the production of isoprenoid precursors [24], were protected against the otherwise toxic effects of prions [23]. Since the formation of lipid rafts and lipid raft-dependent uptake is sensitive to cholesterol depletion [35], we examined the effects of squalestatin-treatment on the trafficking of MoPrP105-132. One possible explanation for the neuroprotective effects of squalestatin, that it prevents ingestion of MoPrP105-132, was excluded by studies that showed that there was no significant difference in the amounts of peptide taken up by untreated and treated cells. However, we did detect a difference in the trafficking of MoPrP105-132 between treated and untreated cells. Squalestatin-treatment of neuroblastoma cells greatly reduced the amounts of MoPrP105-132 that co-localised with either CTxB or with caveolin-1 indicating the most of the peptide was no longer present in lipid rafts. This observation was confirmed by Triton X-100 extractions which showed that most of the MoPrP105-132 peptide was now in the nonraft fraction. Fluorescence microscopy and cell fractionation studies both suggested that in squalestatin-treated cells MoPrP105-132 trafficked down a classical endocytic pathway into lysosomes, avoiding the Golgi/ER. These results are consistent with reports that cholesterol depletion results in the loss of lipid raft functions, including raft-dependent endocytosis and subsequent intracellular trafficking [36].

The neurotoxicity of prion-derived peptides depends on the activation of specific signalling pathways including $\mathrm{PLA}_{2}$ and the COX enzymes that convert AA into PGs [2831]. Furthermore, prion-induced injury is associated with increased levels of $\mathrm{PGE}_{2}[20,21]$. Selective inhibitors indicated the importance of the COX-1 isoform in prionmediated neurotoxicity [28]. In untreated neuroblastoma cells a significant proportion of MoPrP105-132 co-localised with $\mathrm{CPLA}_{2}$ and COX-1, this association was short lived (seen at 5 minutes after the addition of peptide but not after 20 minutes). The brief association observed could be a result of peptide rapidly transiting the COX-1/ cPLA2 containing compartment, or alternatively localisation of these enzymes is known to be transient and dependent on the activation state of the cell [37]. These observations suggest that the association of MoPrP105132 with $\mathrm{CPLA}_{2}$ and COX-1 activates these enzymes leading to the production of toxic second messengers. Pretreatment of neuroblastoma cells with squalestatin reduced the co-localisation between MoPrP105-132 and
$\mathrm{CPLA}_{2}$ or COX-1, and reduced prion-induced $\mathrm{PGE}_{2}$ production [23]. Taken together these observations suggest that in normal neuroblastoma cells MoPrP105-132 accumulates in lipid rafts where they activate the $\mathrm{PLA}_{2} / \mathrm{COX}$ pathway resulting in the production of neurotoxins including $\mathrm{PGE}_{2}[28]$. Thus, the neuroprotective effect of squalestatin treatment may simply be by the dispersal of lipid rafts, which prevent the formation of MoPrP105$132 / \mathrm{PLA}_{2} / \mathrm{COX}-1$ complexes and reduce the production of neurotoxins. Similar effects where found in neuroblastoma cells treated with the PAF antagonist (Hexa-PAF), which protects neurones against prion-mediated neuronal damage [30]. Pre-treatment of neuroblastoma cells with the PAF antagonist reduced the co-localisation between MoPrP105-132 and cPLA ${ }_{2}$ and significantly between MoPrP105-132 and COX-1. This observation is consistent with reports that PAF antagonists reduce $\mathrm{PGE}_{2}$ production in prion peptide treated neuroblastoma cells [38].

\section{Conclusion}

In conclusion, our data demonstrate that in normal neuroblastoma cells the majority of MoPrP105-132 is found in lipid rafts and traffics via a non-classical endocytic, recycling pathway. This pathway involves internalisation via lipid rafts and trafficking into the Golgi and ER. During this process MoPrP105-132 co-localises with the signalling enzymes, CPLA 2 and COX-1, enzymes that are involved in the production of prostaglandins, bioactive lipids closely associated with neuronal death in prion diseases. Treatment of neuroblastoma cells with squalestatin was shown to prevent peptide-induced neurotoxicity but did not prevent internalisation. However squalestatin treatment was associated with altered localisation and trafficking of MoPrP105-132 in neuroblastoma cells. In these cells MoPrP105-132 is not found in lipid rafts, did not associate with CPLA 2 and COX-1, and trafficked into lysosomes. We speculate that the effect of squalestatin in negating prion peptide induced neurotoxicity may result from altered trafficking of MoPrP105-132 thus preventing interactions with specific signalling pathways. This hypothesis is strengthened by the observation that a second neuroprotective drug, Hexa-PAF, also prevented peptide association with CPLA ${ }_{2}$ and COX-1. As altering the trafficking of prion-derived peptides appears to be associated with protection against neurotoxicity, strategies to manipulate intracellular trafficking pathways could lead to novel therapeutic approaches in prion disease.

\section{Methods \\ Cell Lines}

The murine neuroblastoma NB4-1A3 cell line (European Collection of Cell Cultures) was maintained in RPMI1640 (Invitrogen, Paisley, UK) supplemented with $2 \mathrm{mM}$ glutamine and $5 \%$ foetal calf serum (FCS). Cells were dis- 
pensed onto sterilised $13 \mathrm{~mm}$ glass coverslips pre-coated with poly-D-lysine $(50 \mu \mathrm{g} / \mathrm{ml})$ at $3 \times 10^{5}$ cells per well $(24$ well plates) and left to adhere overnight before further use.

\section{Primary neuronal cultures}

Primary cortical neurons were prepared from embryonic day 15.5 mice as previously described [39] and plated onto sterilised $13 \mathrm{~mm}$ glass coverslips pre-coated with poly-D-lysine $(50 \mu \mathrm{g} / \mathrm{ml})$ at $2 \times 10^{6}$ cells per well ( 24 well plates) [39]. After 2 hours, media was changed to neurobasal medium (NBM) containing B27 components (Invitrogen), $2 \mathrm{mM}$ glutamine and $5 \mu \mathrm{M}$ cytosine arabinoside (Sigma, Dorset, UK) to prevent the proliferation of astroglia. Neuronal cultures were used 7 days after plating.

\section{PrP Peptides}

Synthetic PrP peptides were derived from the sequence of murine prion protein (MoPrP105-132; KTNLKHVAGAAAAGAVVGGLGGYMLGSA) [8] as was a control peptide containing the same amino acids in a scrambled order (scrambled MoPrP105-132; NGAGKAGMVGLYGAHGATAKVSLVGALA). Peptides were synthesized by solid-phase chemistry and purified by reverse-phase HPLC (gift from Dr. J. Langeveld, ID-Lelystad/Pepscan Systems, The Netherlands). To enable detection of the peptides, they were labelled with rhodamine, fluorescein or biotin.

\section{Fluorescence microscopy}

NB4 1A3 neuroblastoma cells were incubated with $30 \mu \mathrm{M}$ rhodamine or biotinylated MoPrP105-132 or scrambled peptide conjugated to rhodamine or biotin for 20 to 90 minutes at $37^{\circ} \mathrm{C}$. Biotinylated MoPrP105-132 was detected using streptavidin Texas Red (Vector Laboratories, Peterborough, UK). Lipid rafts were identified using $1 \mu \mathrm{g} / \mathrm{ml} \mathrm{CTxB}$ conjugated to Alexa Fluor 488 (Molecular Probes, The Netherlands) for 30 minutes at $37^{\circ} \mathrm{C}$. FITCdextran (70 kDa; Molecular Probes) was used as a marker for fluid-phase uptake. For intracellular staining, cells were fixed with $1 \%$ paraformaldehyde, Following incubation, cells attached to coverslips were washed once in PBS and fixed in $1 \%$ paraformaldehyde. Lipid rafts were identified using $1 \mu \mathrm{g} / \mathrm{ml} \mathrm{CTxB}$ conjugated to Alexa Fluor 488 (Molecular Probes, The Netherlands) for 30 minutes at $37^{\circ} \mathrm{C}$. For intracellular staining, cells were permeabilised (PBS containing 2\% FCS, 2 mM EDTA, $0.1 \% \mathrm{w} / \mathrm{v}$ saponin) and incubated in blocking buffer (PBS containing 1\% FCS) to prevent non-specific binding. Biotinylated MoPrP105-132 was detected using streptavidin Texas Red (Vector Laboratories, Peterborough, UK). Early endosomes and lysosomes were stained using antibodies specific for the transferrin receptor (TfR-FITC; BD Pharmingen, Oxford, UK) and lysosomal associated membrane protein-1 (LAMP-1-FITC; BD Pharmingen) respectively. The Golgi was stained using GM130 (Santa Cruz Biotechnology, CA, USA), a marker for the Golgi, and visualised using anti-rabbit FITC (Vector Laboratories). In addition, the ER was stained using anti-Grp78 (Stressgen Biotechnology, San Diego, USA) and visualised using anti-rabbit FITC (Vector Laboratories). Anti-COX-1FITC (BD Biosciences) and anti-CPLA ${ }_{2}$-FITC (Santa Cruz Biotechnology, California, USA) were used for investigating signalling enzymes. Vectashieid containing DAPI (Vector Laboratories) was used to stain cell nuclei. Coverslips were mounted onto glass slides (Speci-Microsystems Ltd, Surrey, UK) and fluorescence microscopy was performed with an Axiovert S-100 Zeiss microscope using a $63 \times$ oil immersion lens. Serial images in $\mathrm{z}$ were captured using a Hamamatsu Orca LCD camera and unprocessed images (additional file 4) were deconvolved using OpenLab software (Improvision, Coventry, UK). Images shown are representative of at least 10 fields of view, with a cell density of typically 5 - 10 cells per field. The degree of colocalisation in fluorescent deconvolved images was evaluated from the number of co-localised pixels within a given cell for a minimum of 3 representative cells, as determined by OpenLab software. For drug treatment, cells were pre-treated under the following conditions prior to the addition of prion peptides: $1 \mu \mathrm{M}$ squalestatin (GlaxoSmithKline, Herts, UK) or $2 \mu \mathrm{M}$ 1-O-alkyl-2-acetyl-snglycerol-3-phospho-(N,N,N-trimethyl)-hexanolamine (Hexa-PAF) (Novabiochem, Nottingham, UK) overnight at $37^{\circ} \mathrm{C}$ before use.

\section{FRET}

NB4 1A3 cells were incubated with $30 \mu \mathrm{M}$ MoPrP105-132 conjugated to rhodamine and either $\mathrm{CTxB}$ conjugated to Alexa Fluor 488, or FITC-labelled caveolin-1 for $30 \mathrm{~min}$ utes at $37^{\circ} \mathrm{C}$. Fluorescence microscopy was performed with an Olympus BX50 fluorescence microscope equipped with appropriate excitation and emission filter sets. Images representing donor fluorescence, acceptor fluorescence (rhodamine) and FRET signal were taken. Donor and acceptor bleed through values were calculated and the FRET signal quantified and FRET images generated using OpenLab FRET module software [40].

\section{Lipid raft isolation}

Lipid raft isolation was performed as previously described [41]. Briefly, NB4 1A3 cells were incubated with $30 \mu \mathrm{M}$ MoPrP105-132-FITC for 30 minutes, before being lysed with distilled $\mathrm{H}_{2} \mathrm{O}$ and centrifuged ( 10 minutes at $1,000 \times$ g). Pellets were suspended in 1\% Triton-X 100 in PBS plus $5 \mathrm{mM}$ phenylmethyl sulfonyl fluoride (PMSF) and incubated for 30 minutes on ice. After centrifugation (10 minutes at $14,000 \times g$ ), the supernatant was kept as the nonlipid raft fraction. Pellets were suspended in extraction buffer (10 mM Tris-HCL, $10 \mathrm{mM} \mathrm{NaCl}, 10 \mathrm{mM}$ EDTA, $0.5 \%$ Nonidet P-40 and $0.5 \%$ Sodium Deoxycholate) and 
centrifuged $(10$ minutes at $14,000 \times g)$. The supernatant obtained contained the lipid raft fraction. Using western blot analysis, fractions were transferred onto nitrocellulose and probed for MoPrP105-132 using anti-FITC horseradish peroxidase (HRP;Molecular Probes). Fractions were probed using anti-TfR-FITC and anti-Caveolin1-FITC (Santa Cruz Biotechnology) and detected using anti-FITC HRP. Fractions were visualised using enhanced chemiluminescence (ECL). Using slot blot analysis, ganglioside-1 (GM1) was detected using CTxB-FITC (Sigma) followed by anti-FITC HRP. For drug treatment, NB4 1A3 cells were pre-treated with squalestatin as described above.

\section{Cell homogenisation and fractionation}

NBA 1A3 cells were fractionated using a combination of magnetic isolation of lysosomes [26] and gradient centrifugation $[42,43]$. Cells were incubated with iron dextran, produced from $40 \mathrm{kDa}$ dextran as previously described [44] for 1 hour at $37^{\circ} \mathrm{C}$. Media containing iron dextran was removed and replaced with fresh medium and incubated overnight. After incubation with $30 \mu \mathrm{M}$ MoPrP105132-FITC for 1 hour at $37^{\circ} \mathrm{C}, \mathrm{NB} 41 \mathrm{~A} 3$ cells were scraped into cold $\left(4^{\circ} \mathrm{C}\right)$ homogenisation buffer $(0.5 \mathrm{mM}$ EGTA, $0.5 \mathrm{mM}$ EDTA, $20 \mathrm{mM}$ HEPES, $0.05 \%$ gelatin and 250 $\mathrm{mM}$ sucrose). Cells were centrifuged $(250 \times g$ for $8 \mathrm{~min}$ utes) and suspended in $1 \mathrm{ml}$ homogenisation buffer and then lysed by repeat passage through a $25 \mathrm{G}$ syringe. Nuclei and large fragments were removed by low speed centrifugation $(110 \times g$ for 6 minutes $)$ and the resultant supernatant was then applied to a MACS column (Miltenyi Biotec, Surrey, UK) and allowed to run through the column by gravity to give a non-lysosomal fraction. The column was then washed with homogenisation buffer before being removed from the magnet and the remaining homogenate was eluted, giving a lysosomal fraction [F3]. Using a density gradient technique [26], the non-lysosomal fraction was layered on top of a two step 17\% (w/w) Percoll (Amersham Biosciences, UK), 64\% $(\mathrm{w} / \mathrm{w})$ sucrose cushion. After ultracentrifugation (1 hour at $80,000 \times g$ ) using a Beckman Type 70Ti fixed angle rotor, bands containing endosomal organelles [F1] and Golgi and ER [F2] were removed and concentrated by centrifugation $(100,000 \times g$ for 30 minutes $)$. The protein content of these fractions were standardised following protein assay (Pierce MicroBCA kit; Pierce, Cheshire, UK). Gel electrophoresis of the endosomal fractions was performed using precast $4-12 \%$ Bis-Tris gradient gels with 2-(N-morpholino)ethanesulfonate (MES) running buffer (NuPAGE; Invitrogen) and proteins were transferred onto nitrocellulose, using western blot analysis and probed for MoPrP105-132 using anti-FITC HRP. Secondary antibody anti-FITC HRP was used to detect TfR-FITC and LAMP-1FITC and fractions were visualised using enhanced chemi- luminescence ECL. For drug treatment, NB4 1A3 cells were pre-treated with squalestatin as described above.

\section{Flow Cytometry}

NB4 1A3 cells were incubated with FITC-conjugated MoPrP105-132 for 30 minutes at $37^{\circ} \mathrm{C}$. Cells were then centrifuged and fixed with $1 \%$ paraformaldehyde for 10 minutes, washed and suspended in FACS flow (BD, Pharmingen). Cell associated fluorescence was determined by FACS analysis (FACSCalibur; Becton Dickinson), and expressed as arbitrary fluorescence units (mean fluorescence intensity) using Cell Quest software. Flow cytometry was also performed on MoPrP105-132-FITC treated, NB4 1A3 cells that had been pre-treated with either squalestatin as described above.

\section{Statistical Analysis}

Treatment effects were compared using one and two way analysis of variance techniques as appropriate. For all statistical tests, significance was set at the $1 \%$ level. Percentage co-localisation in fluorescent deconvolved images was determined by counting the number of co-localised pixels against the number of pixels that did not co-localise, using OpenLab software. Percentage of co-localisation was presented as $\% \pm$ standard deviation (SD), which was calculated after counting a minimum of 3 cells.

\section{List of abbreviations}

PrPsc, Scrapie isoform of PrP; PrPC, Cellular isoform of prion protein; CtmPrP, transmembrane form of PrP; MoPrP, murine prion protein; GPI, glycosylphophatidylinositol; CTxB, cholera toxin subunit B; ER, Endoplasmic Reticulum; PG, prostaglandin; $\mathrm{PLA}_{2}$, phospholipase $\mathrm{A}_{2}$; AA, Arachidonic acid; COX, cyclo-oxygenase; PAF, platelet activating factor; $\mathrm{CPLA}_{2}$, cytoplasmic phospholipase $\mathrm{A}_{2}$; NBM, Neurobasal medium; FCS, Fetal calf serum; TfR, transferrin receptor; Lamp-1, lysosomal associated membrane protein-1; FRET, fluorescence resonance energy transfer; PMSF, phenylmethyl sulfonyl fluoride; HRP, horseradish peroxidase; ECL, enhanced chemiluminenscence; GM1, ganglioside-1.

\section{Authors' contributions}

RKW carried out the fluorescence microscopy, fractionation studies and statistical described and drafted the manuscript. RB produced the labelled peptides for the study. $\mathrm{JMB}, \mathrm{RB}, \mathrm{AW}$ and $\mathrm{CB}$ conceived of the study, and participated in its design and coordination and helped to draft the manuscript. All authors read and approved the final manuscript. 


\section{Additional material}

\section{Additional file 1}

MoPrP105-132 is found in lipid rafts in primary neurons. Primary neurons were treated with rhodamine-labeled MoPrP105-132 (A) or control scrambled peptide (B) and Alexa Fluor 488 labeled CTXB as described in Figure 1.

Click here for file

[http://www.biomedcentral.com/content/supplementary/14712202-8-99-S1.jpeg]

\section{Additional file 2}

MoPrP105-132 avoids early endosomes and lysosomes in primary neurons. Primary neurons were treated with biotin-labeled MoPrP105-132 and transferrin positive early endosomes (A) and LAMP-1 positive lysosomes (B) identified as described in Figure 2

Click here for file

[http://www.biomedcentral.com/content/supplementary/14712202-8-99-S2.jpeg]

\section{Additional file 3}

Neurotoxicity of MoPrP105-132 and inhibition by Squalestatin. NB4 neuroblastoma cells were plated at $3 \times 10^{4}$ cells/well into 96-well microtiter plates and allowed to adhere overnight. The following day, cells were treated with (A) either MoPrP105-132 or rhodamine labeled MoPrP105132 and cell viability determined $24 \mathrm{~h}$ later. (B) Alternatively cells were treated for $24 \mathrm{~h}$ with $100 \mathrm{nM}$ squalestatin or carrier (DMSO) prior to addition of MoPrP105-132 and incubation for $24 \mathrm{~h}$. Cell viability was determined using the MTT method Optical density was measured at 595 $n m$, and results calculated by reference to untreated cells.

Click here for file

[http://www.biomedcentral.com/content/supplementary/14712202-8-99-S3.pdf]

\section{Additional file 4}

Raw images of the data from manuscript Figure 1A. NB4 neuroblastoma cells were incubated for 30 minutes with $30 \mu \mathrm{M}$ rhodamine-labeled MoPrP105-132 and lipid rafts revealed by CTxB-Alexa Fluor 488 staining as described in Materials and Methods. Serial sections of the stained cells were taken at $0.2 \mu \mathrm{m}$ intervals through the cell centre. OpenLab software was used to perform digital deconvolution to remove out of focus light from images and also to determine co-localisation.

Click here for file

[http://www.biomedcentral.com/content/supplementary/14712202-8-99-S4.jpeg]

\section{Acknowledgements}

This work was supported by Scottish Hospitals Endowments Research Trust (SHERT; Grant number RG48/02), Tenovus, Scotland (Grant Number S04/6) and by the European Commission and FP6 "Neuroprion" Network of Excellence.

\section{References}

I. Prusiner SB: Novel proteinaceous infectious particles cause scrapie. Science 1982, 216(4542): I36-| 44.

2. Horwich AL, Weissman JS: Deadly conformations - protein misfolding in prion disease. Cell 1997, 89(4):499-5I0.

3. Prusiner SB: Prions. Proc Natl Acad Sci USA 1998 95(23): 13363-13383.
4. Beisel CE, Morens DM: Variant Creutzfeldt-Jakob disease and the acquired and transmissible spongiform encephalopathies. Clin Infect Dis 2004, 38(5):697-704.

5. Jeffrey M, McGovern G, Goodsir CM, Brown KL, Bruce ME: Sites of prion protein accumulation in scrapie-infected mouse spleen revealed by immuno-electron microscopy. J Pathol 2000, I 9 |(3):323-332.

6. Van Everbroeck B, Pals P, Martin JJ, Cras P: Transmissible spongiform encephalopathies: the story of a pathogenic protein. Peptides 2002, 23(7): | 35|-1359.

7. Forloni G, Angeretti N, Chiesa R, Monzani E, Salmona M, Bugiani O, Tagliavini F: Neurotoxicity of a prion protein fragment. Nature 1993, 362(6420):543-546.

8. Haik S, Peyrin JM, Lins L, Rosseneu MY, Brasseur R, Langeveld JP, Tagliavini F, Deslys JP, Lasmezas C, Dormont D: Neurotoxicity of the putative transmembrane domain of the prion protein. Neurobiol Dis 2000, 7(6 Pt B):644-656.

9. Stewart RS, Harris DA: A transmembrane form of the prion protein is localized in the golgi apparatus of neurons. J Biol Chem 2005, 280(16): I 5855-64.

10. Chiesa R, Harris DA: Prion diseases: what is the neurotoxic molecule? Neurobiol Dis 200I, 8(5):743-763.

II. Hegde RS, Rane NS: Prion protein trafficking and the development of neurodegeneration. Trends Neurosci 2003, 26(7):337-339.

12. Nichols BJ: GMI-containing lipid rafts are depleted within clathrin-coated pits. Curr Biol 2003, I3(8):686-690.

13. Sugimoto $Y$, Ninomiya $H$, Ohsaki Y, Higaki K, Davies JP, loannou YA, Ohno K: Accumulation of cholera toxin and GMI ganglioside in the early endosome of Niemann-Pick Cl-deficient cells. Proc Natl Acad Sci USA 200 I, 98(22): I 239। - 2396.

14. Le PU, Nabi IR: Distinct caveolae-mediated endocytic pathways target the Golgi apparatus and the endoplasmic reticulum. I Cell Sci 2003, II 6(Pt 6): 1059-I07I.

15. Pang H, Le PU, Nabi IR: Ganglioside GMI levels are a determinant of the extent of caveolae/raft-dependent endocytosis of cholera toxin to the Golgi apparatus. J Cell Sci 2004, I I 7(Pt 8): $|42|-\mid 430$

16. Simons K, Ehehalt R: Cholesterol, lipid rafts, and disease. J Clin Invest 2002, I I 0(5):597-603.

17. Nichols B: Caveosomes and endocytosis of lipid rafts. J Cell Sci 2003, I I 6(Pt 23):4707-47|4.

18. Quest AF, Leyton L, Parraga M: Caveolins, caveolae, and lipid rafts in cellular transport, signaling, and disease. Biochem Cell Biol 2004, 82(I): I29-I44.

19. Sowa G, Pypaert M, Sessa WC: Distinction between signaling mechanisms in lipid rafts vs. caveolae. Proc Natl Acad Sci USA 200I, 98(24): I 4072-14077.

20. Minghetti L, Cardone F, Greco A, Puopolo M, Levi G, Green AJ, Knight R, Pocchiari M: Increased CSF levels of prostaglandin E(2) in variant Creutzfeldt-Jakob disease. Neurology 2002, 58(I): I27-I29.

21. Minghetti L, Greco A, Cardone F, Puopolo M, Ladogana A, Almonti S, Cunningham C, Perry VH, Pocchiari M, Levi G: Increased brain synthesis of prostaglandin E2 and F2-isoprostane in human and experimental transmissible spongiform encephalopathies. J Neuropathol Exp Neurol 2000, 59(10):866-87I.

22. Taraboulos A, Scott M, Semenov A, Avrahami D, Laszlo L, Prusiner SB, Avraham D: Cholesterol depletion and modification of COOH-terminal targeting sequence of the prion protein inhibit formation of the scrapie isoform. J Cell Biol 1995, I29(I): $12 \mid-132$.

23. Bate C, Salmona M, Diomede L, Williams A: Squalestatin cures prion-infected neurones and protects against prion neurotoxicity. J Biol Chem 2004, 279( (15): I 4984-I 4990.

24. Baxter A, Fitzgerald BJ, Hutson JL, McCarthy AD, Motteram JM, Ross BC, Sapra M, Snowden MA, Watson NS, Williams RJ, et al.: Squalestatin I, a potent inhibitor of squalene synthase, which lowers serum cholesterol in vivo. I Biol Chem 1992, 267(17): II705-II708

25. Nichols BJ: A distinct class of endosome mediates clathrinindependent endocytosis to the Golgi complex. Nat Cell Biol 2002, 4(5):374-378.

26. Tjelle TE, Brech A, Juvet LK, Griffiths G, Berg T: Isolation and characterization of early endosomes, late endosomes and termi- 
nal lysosomes: their role in protein degradation. J Cell Sci 1996, 109(Pt

I 2):2905-29|4.

27. Tjelle TE, Brech A, Juvet LK, Griffiths $G$, Berg $T$ : Isolation and characterization of early endosomes, late endosomes and terminal lysosomes: their role in protein degradation. J Cell Sci 1996, I09(Pt I 2):2905-29|4.

28. Bate C, Rutherford S, Gravenor M, Reid S, Williams A: Cyclo-oxygenase inhibitors protect against prion-induced neurotoxicity in vitro. Neuroreport 2002, I3(I 5): 1933-1938.

29. Bate C, Reid S, Williams A: Phospholipase A2 inhibitors or platelet-activating factor antagonists prevent prion replication. Biol Chem 2004, 279(35):36405-364II.

30. Bate C, Salmona M, Williams A: The role of platelet activating factor in prion and amyloid-beta neurotoxicity. Neuroreport 2004, I5(3):509-5I3.

31. Bate C, Williams A: Role of glycosylphosphatidylinositols in the activation of phospholipase $A 2$ and the neurotoxicity of prions. J Gen Virol 2004, 85(Pt I 2):3797-3804.

32. Lee KS, Linden R, Prado MA, Brentani RR, Martins VR: Towards cellular receptors for prions. Rev Med Virol 2003, I3(6):399-408.

33. Conner SD, Schmid SL: Regulated portals of entry into the cell. Nature 2003, 422(6927):37-44.

34. Luetterforst R, Stang E, Zorzi N, Carozzi A, Way M, Parton RG: Molecular characterization of caveolin association with the Golgi complex: identification of a cis-Golgi targeting domain in the caveolin molecule. J Cell Biol I999, I45(7): I443-I459.

35. Murata M, Peranen J, Schreiner R, Wieland F, Kurzchalia TV, Simons $\mathrm{K}$ : VIP2 I/caveolin is a cholesterol-binding protein. Proc Natl Acad Sci USA 1995, 92(22): 10339-10343.

36. Nichols BJ, Kenworthy AK, Polishchuk RS, Lodge R, Roberts TH, Hirschberg K, Phair RD, Lippincott-Schwartz J: Rapid cycling of lipid raft markers between the cell surface and Golgi complex. Cell Biol 200I, I 53(3):529-54I.

37. Grewal S, Ponnambalam S, Walker JH: Association of cPLA2alpha and COX-I with the Golgi apparatus of A549 human lung epithelial cells. J Cell Sci 2003, I I6(Pt II):2303-23I0.

38. Bate C, Salmona M, Williams A: Ginkgolide B inhibits the neurotoxicity of prions or amyloid-beta I-42. I Neuroinflammation 2004, I(I):4.

39. Bate $\mathrm{C}$, Reid S, Williams A: Killing of prion-damaged neurones by microglia. Neuroreport 200I, I2(I I):2589-2594.

40. Xia Z, Liu Y: Reliable and global measurement of fluorescence resonance energy transfer using fluorescence microscopes. Biophys J 200I, 8 I (4):2395-2402.

4I. Madore N, Smith KL, Graham CH, Jen A, Brady K, Hall S, Morris R: Functionally different GPI proteins are organized in different domains on the neuronal surface. Embo J 1999, I 8(24):6917-6926.

42. Caimi L, Marchesini S, Aleo MF, Bresciani R, Monti E, Casella A, Giudici ML, Preti A: Rapid preparation of a distinct lysosomal population from myelinating mouse brain using Percoll gradients. J Neurochem 1989, 52(6): $1722-1728$.

43. Ohshita T, Kido H: Simple preparation of rat brain lysosomes and their proteolytic properties. Anal Biochem 1995, 230(I):4I-47.

44. Kronick $P$, Gilpin RW: Use of superparamagnetic particles for isolation of cells. J Biochem Biophys Methods 1986, I 2(I-2):73-80. http://www.biomedcentral.com/1471-2202/8/99 